\title{
Steroid injections added to the usual treatment of lumbar radicular syndrome: a pragmatic randomized controlled trial in general practice
}

\author{
Antje Spijker-Huiges, Jan C Winters, Marten van Wijhe and Klaas Groenier
}

\begin{abstract}
Background: Lumbosacral radicular syndrome (LRS) is a self-limiting, benign, painful and impairing condition caused by lumbar disc herniation and inflammatory processes around the nerve root. Segmental epidural steroid injections (SESIs) are helpful to reduce radicular pain on a short-term basis. It is unknown whether SESIs are an effective addition to usual pain treatment of LRS in general practice. In our study, we assessed the effectiveness of SESIs on pain and disability as an addition to usual care for acute LRS in general practice.

Methods: A pragmatic, single-blinded, randomized controlled trial in Dutch general practice was conducted. Circumstances of daily practice were closely followed. Care as usual (CAU) was compared to care as usual combined with an additional SESI in 63 patients in the acute phase of LRS. To detect a minimal clinically important difference of 1.2 points on a numerical rating scale for back pain and a common within-group standard deviation of 1.7 with a two-tailed alpha of 0.05 and a power of 0.80 , we needed 33 subjects in each group. Statistical analysis was carried out using mixed models.
\end{abstract}

Results: A small significant effect in favour of the intervention, corrected for age, sex and baseline values, was found for back pain, impairment and Roland-Morris disability score. The differences, though statistically significant, were too small to be considered clinically relevant. Patients from the intervention group were significantly more satisfied with the received treatment than patients from the control group.

Conclusion: We found a small, statistically significant, but not clinically relevant positive effect of SESIs on back pain, impairment and disability in acute LRS. We do not recommend implementing SESIs as an additional regular treatment option in general practice.

Keywords: Lumbosacral radicular syndrome, Sciatica, General practice, Pain treatment, Epidural injections

\section{Background}

Lumbosacral radicular syndrome (LRS) is defined as pain, radiating from the back into the leg, ("sciatica") in combination with Lasègue's sign and/or neurological symptoms originating from a single nerve root. In the Netherlands, LRS is treated by general practitioners (GPs) who adhere to the Dutch College of General Practitioner's Guideline on LRS. According to this guideline, treatment of LRS consists of pain treatment by taking analgesics as needed, and maintaining normal daily activities as much as possible. The prognosis of LRS is favourable: within

\footnotetext{
*Correspondence: a.spijker-huiges@umcg.nl

Department of General Practice, University Medical Centre Groningen, Postbus 196, FA20, 9700 AD Groningen, The Netherlands
}

eight weeks, $80 \%$ of patients have reached bearable pain levels and resumed their work [1]. Some patients, however, do not adequately respond to conservative therapy during and after this period [2]. In $25 \%$ of patients, radicular pain becomes chronic [1]. Since there are few effective and evidence-based conservative pain treatments for LRS, caring for these patients can be difficult for GPs $[2,3]$.

LRS is most commonly caused by protrusion of a lumbar intervertebral disc, which results in an inflammatory response around the nerve root $[1,4]$. This inflammatory process is the cause of the radicular pain, rather than mechanical compression [5-8]. Local anti-inflammatory drugs may lessen inflammation and pain, making it easier for patients to profit from the favourable prognosis. 
Segmental epidural steroid injections (SESIs) and selective nerve root blocks (SNRBs) are examples of local antiinflammatory treatment. SESIs are not recommended in the Dutch guidelines for general practitioners, but still the intervention is applied as a pain treatment for LRS in the Netherlands.

Efficacy of SESIs in LRS is controversial. Some studies are underpowered, others lack methodological quality to justify definite conclusions [2,9-12]. In trials that included patients in the acute phase of well-defined radicular syndrome ("sciatica"), SESIs turned out to be more effective than placebo in reducing pain and hastening return to normal daily activities $[2,5,8,13-22]$.

Since patients in the acute phase of LRS are cared for by GPs, SESIs are a possibly useful treatment option in general practice. Most RCTs, however, have been conducted to assess efficacy rather than effectiveness (i.e. placebo-controlled double blinded trials rather than pragmatic trials), in specialist practice, in heterogeneous patient groups, with a short-term follow-up and using a single measuring moment. To our knowledge, no study has assessed effectiveness in general practice, with multiple measuring points and a long term follow-up, in a homogeneous patient group. We assessed the effectiveness of adding SESIs to usual pain treatment for patients with acute LRS in general practice, by means of a pragmatic randomized controlled trial measuring pain, disability and recovery in acute LRS patients with profound sciatica.

\section{Methods}

Our trial took place in and around the city of Groningen, the Netherlands, in 41 general practices with 76 participating GPs. Patients were recruited between January $1^{\text {st }} 2005$ and December $31^{\text {st }} 2007$ and followed for one year. This study was approved by the Medical-Ethical Committee of the University Medical Center Groningen in 2005, code 2005/154, and was registered in the Dutch trial register as SLURP, code NTR342. This study was funded by the UMCG, there was no additional funding from external sources.

Our research question calls for a pragmatic study design, which demands that real life conditions are followed as closely as possible. Usual care was therefore not standardized but defined as the treatment decided on by the patients and their GPs. Since Dutch GPs generally adhere to the Dutch College of General Practitioner's guidelines, usual care consisted of advice and analgesic medication and/or referral as needed $[1,23]$. The GPs' diagnosis of LRS was not evaluated by further specialist physical examination, except to determine the level at which the SESI was to be administered. Patients and caregivers were not blinded.

Inclusion criteria were a diagnosis of LRS established by the GP, complaints of LRS for at least two weeks and no more than four weeks duration and patient age between 18 and 60 years. The upper age limit of 60 was chosen because complications of epidural injections are more common in the over 60 age group, due to osteoporosis. Exclusion criteria were a history of spinal surgery or spinal trauma, maintenance therapy with corticosteroids or anticoagulants, bleeding disorder, cauda equina syndrome, a body mass index of more than 35 , inadequate mastery of the Dutch language, allergy to corticosteroids, pregnancy or an active wish to become pregnant, breastfeeding and mental disability. Patients with insulin-dependent diabetes mellitus were not excluded but instructed to measure their serum glucose levels regularly in the 48 hours after the intervention.

Patients in whom the GP established the diagnosis of LRS were given written information on the study, a baseline symptom questionnaire and an informed consent form. Patients were asked to complete the questionnaire and the informed consent form and send them to the research centre. Upon receiving this information, subjects were contacted by the primary researcher to check inclusion and exclusion criteria with a protocolled inclusion form. In the absence of exclusion criteria, the inclusion form was completed.

Randomization was performed by an independent colleague with no further involvement in the study. Preprepared, sequentially numbered, opaque, sealed envelopes containing stickers labelled either "SESI" or "CAU", balanced after 40 assignments, were used. Upon randomisation, the consecutive envelope was opened and the sticker with the allocated treatment was fixed on the completed inclusion form. Inclusion forms, containing personal patient information, were coded and kept separately from follow-up questionnaires. To keep the primary researcher blinded until after the final analysis of the results, follow-up questionnaires were provided with the same codes but contained no personal patient information.

Patients allocated to the intervention group were presented to the department of anaesthesiology of the University Medical Centre Groningen (UMCG). SESIs were administered by a non-involved anaesthesiologist within 48 hours after randomisation. SESIs consisted of 80 milligrams of triamcinolone in 10 millilitres of normal saline and were administered using a lumbar translaminar approach without additional imaging, one level above the presumed LRS in either sitting or lateral position. The skin was anaesthetised with lidocaine, but no local anaesthetics were injected epidurally to avoid problems with mobility and bladder emptying. After the injection, patients were referred back to their GPs for further usual care. When a patient was randomized to the CAU-group the GP provided usual care from the start. The translaminar injection technique without additional imaging, rather than a transforaminal approach 
with fluoroscopic guidance and administering of local anaesthetics, was chosen because of the pragmatic study design - given the shorter waiting time and better accessibility, the intervention would be applied this way in normal practice as well.

Follow-up in both groups was performed using postal questionnaires regarding pain, disability, and satisfaction with treatment, measured at 2, 4, 6, 13, 26 and 52 weeks after the start of the treatment. The 24-point RolandMorris Disability Questionnaire (RMDQ) was used for measuring disability $[24,25]$. For measuring pain and self-perceived impairment, a numeric rating scale (NRS) from 0 to 10 was used, where 0 meant no pain/impairment and 10 meant the worst pain/impairment imaginable. For measuring satisfaction with treatment, we asked patients to grade their treatment on a scale from 0 to 10 , where 0 meant very poor and 10 meant excellent. All variables were measured at every time point. As minimal clinically important differences in the interpretation of the results, a reduction of $30 \%$ from baseline was used for the RMDQ-score and 2.0 was used for the NRS pain and impairment scores [24-28].

Power calculations were based on the NRS back pain score at four weeks from the start of the treatment. A difference in NRS back pain score of 1,2 - 2,0 is considered clinically relevant in primary care attendants with low back pain [29-32]. To minimize the risk of underpowering our study, an MCID of 1.2 was used for the sample size calculations. The mean standard deviation of VAS scores in patients with moderate pain is approximately 1,7 [33].

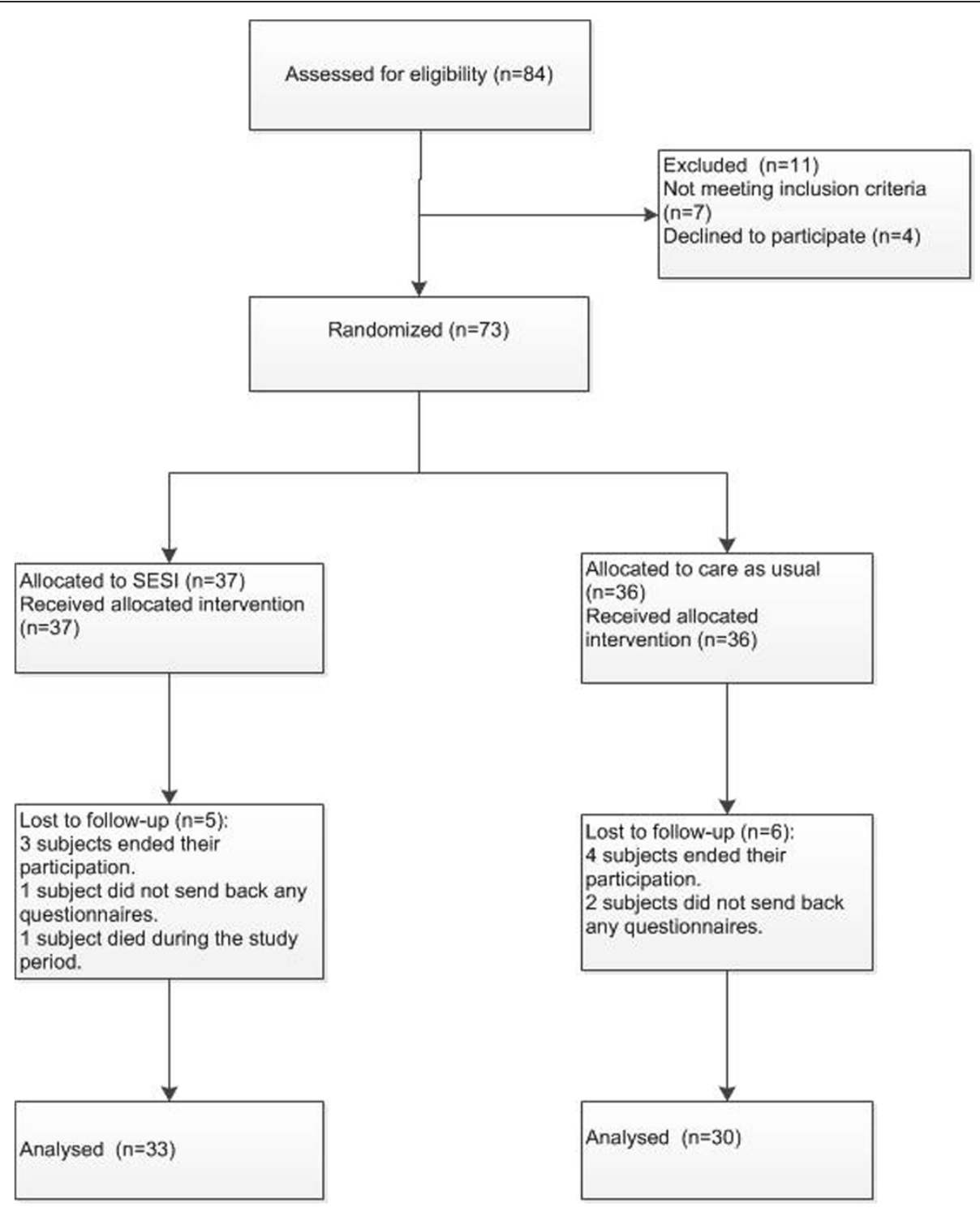

Figure 1 CONSORT population flow schedule. 
Table 1 Mean RMDQ and NRS scores of study participants for every measuring moment in the follow-up period

\begin{tabular}{|c|c|c|c|c|c|c|c|}
\hline Follow-up time (weeks) & 0 & 2 & 4 & 6 & 13 & 26 & 52 \\
\hline \multicolumn{8}{|l|}{ RMDQ score } \\
\hline Intervention group mean (SD) & $16.5(4.2)$ & $10.7(7.1)$ & $8.9(6.8)$ & $8.0(6.8)$ & $5.3(5.9)$ & $3.0(4.5)$ & $2.3(3.7)$ \\
\hline Control group mean (SD) & $14.5(6.1)$ & $12.3(6.1)$ & $10.5(7.0)$ & $8.1(6.3)$ & $7.6(6.3)$ & $5.4(6.5)$ & $4.1(6.2)$ \\
\hline \multicolumn{8}{|l|}{ NRS back pain } \\
\hline Intervention group mean (SD) & $6.2(2.6)$ & $3.3(2.9)$ & $3.3(3.0)$ & $2.5(2.6)$ & $2.1(2.5)$ & $1.9(2.5)$ & $1.3(1.9)$ \\
\hline Control group mean (SD) & $4.5(2.7)$ & $4.1(3.0)$ & $3.6(2.7)$ & $2.8(2.3)$ & $3.0(3.0)$ & $2.0(2.4)$ & $2.0(2.9)$ \\
\hline \multicolumn{8}{|l|}{ NRS leg pain } \\
\hline Intervention group mean (SD) & $7.8(1.7)$ & $4.2(3.1)$ & $3.8(3.3)$ & $2.6(2.5)$ & $1.6(2.5)$ & $1.6(2.4)$ & $1.0(2.0)$ \\
\hline Control group mean (SD) & $6.4(2.3)$ & $4.7(3.1)$ & $3.9(2.8)$ & $2.9(2.5)$ & $2.7(2.8)$ & $1.9(2.5)$ & $1.4(2.2)$ \\
\hline \multicolumn{8}{|l|}{ NRS pain during day } \\
\hline Intervention group mean (SD) & $7.7(1.6)$ & $4.9(3.1)$ & $4.5(3.2)$ & $3.1(2.7)$ & $2.4(2.7)$ & $2.2(2.6)$ & $1.2(2.0)$ \\
\hline Control group mean (SD) & $6.2(2.1)$ & $5.1(2.8)$ & $4.2(2.6)$ & $3.3(2.4)$ & $3.1(2.9)$ & $2.2(2.3)$ & $2.2(3.0)$ \\
\hline \multicolumn{8}{|l|}{ NRS pain during night } \\
\hline Intervention group mean (SD) & $6.4(2.6)$ & $3.6(3.2)$ & $3.7(3.0)$ & $2.5(2.5)$ & $1.7(2.6)$ & $1.8(2.3)$ & $0.8(1.7)$ \\
\hline Control group mean (SD) & $5.7(2.7)$ & $4.3(3.0)$ & $3.0(2.8)$ & $2.6(2.5)$ & $2.6(2.9)$ & $1.9(2.5)$ & $1.8(2.9)$ \\
\hline \multicolumn{8}{|l|}{ NRS total pain } \\
\hline Intervention group mean (SD) & $7.7(1.2)$ & $5.0(2.9)$ & $4.2(3.0)$ & $3.3(2.5)$ & $2.5(2.5)$ & $2.3(2.5)$ & $1.3(2.0)$ \\
\hline Control group mean (SD) & $6.9(1.7)$ & $5.3(2.6)$ & $4.5(2.8)$ & $3.7(2.5)$ & $3.2(2.8)$ & $2.3(2.4)$ & $2.1(3.0)$ \\
\hline \multicolumn{8}{|l|}{ NRS impairment } \\
\hline Intervention group mean (SD) & $7.8(1.6)$ & $5.2(3.2)$ & $4.0(3.1)$ & $3.0(2.8)$ & $2.6(2.9)$ & $1.7(2.2)$ & $1.0(1.6)$ \\
\hline Control group mean (SD) & $6.7(2.2)$ & $5.2(2.8)$ & $4.7(2.8)$ & $3.3(2.9)$ & $3.2(2.9)$ & $2.1(2.3)$ & $1.9(2.6)$ \\
\hline
\end{tabular}

To detect a difference of 1.2 and a common within-group standard deviation of 1.7 with a two-tailed alpha of 0.05 and a power of 0.80 , we needed 33 subjects in each group. To compensate for anticipated lost to follow-up, we intended to include 40 subjects in each group.

This study was performed to achieve two goals. The first goal of the study was to test the difference over time between the means of the two treatments. The second goal of the study was to estimate the differences between the means of the two treatments at every time point of measurement. On average, a study of this design would enable us to report the mean difference with a precision (95.0\% confidence level) of plus/minus 0.84 points.

All analyses were performed using an intention-to-treat basis. Mixed model regression analysis was performed using SAS 9.2 PROC MIXED. No data imputation is necessary using this model [34]. Patients were a random factor in the model and treatment a fixed factor. For every outcome variable, treatment and time of measurement as independent variables were tested with sex, age and baseline-values as covariates to account for non-balance in the randomization.

Table 2 Estimated differences between group means

\begin{tabular}{|c|c|c|c|c|c|}
\hline Variable & Estimated difference & Standard error & $P|t|$ & $95 \% \mathrm{Cl}-$ & $95 \% \mathrm{Cl}+$ \\
\hline RMDQ-score & 2,5004 & 1,0435 & 0,0173 & 0,4551 & 4,5456 \\
\hline NRS back pain & 1,1165 & 0,4389 & 0,0115 & 0,2562 & 1,9767 \\
\hline NRS leg pain & 0,6717 & 0,5100 & 0,1890 & $-0,3279$ & 1,6713 \\
\hline NRS pain during the day & 0,6563 & 0,5186 & 0,2068 & $-0,3601$ & 1,6727 \\
\hline NRS pain during the night & 0,5285 & 0,4741 & 0,2659 & $-0,4007$ & 1,4577 \\
\hline NRS total pain & 0,6890 & 0,4729 & 0,1463 & $-0,2378$ & 1,6158 \\
\hline NRS impairment & 1,0254 & 0,4867 & 0,0361 & 0,0714 & 1,9793 \\
\hline
\end{tabular}

The differences between group means calculated by the mixed models analysis, over the entire course of the study period using linear regression. In this repeated measures regression analysis, differences between groups are calculated based on the study outcomes, corrected for baseline values, to estimate true values in the random population. We found significant differences between group means for RMDQ-score, NRS back pain score and NRS score for self-perceived impairment. These differences are statistically significant but too small to be considered clinically relevant. 

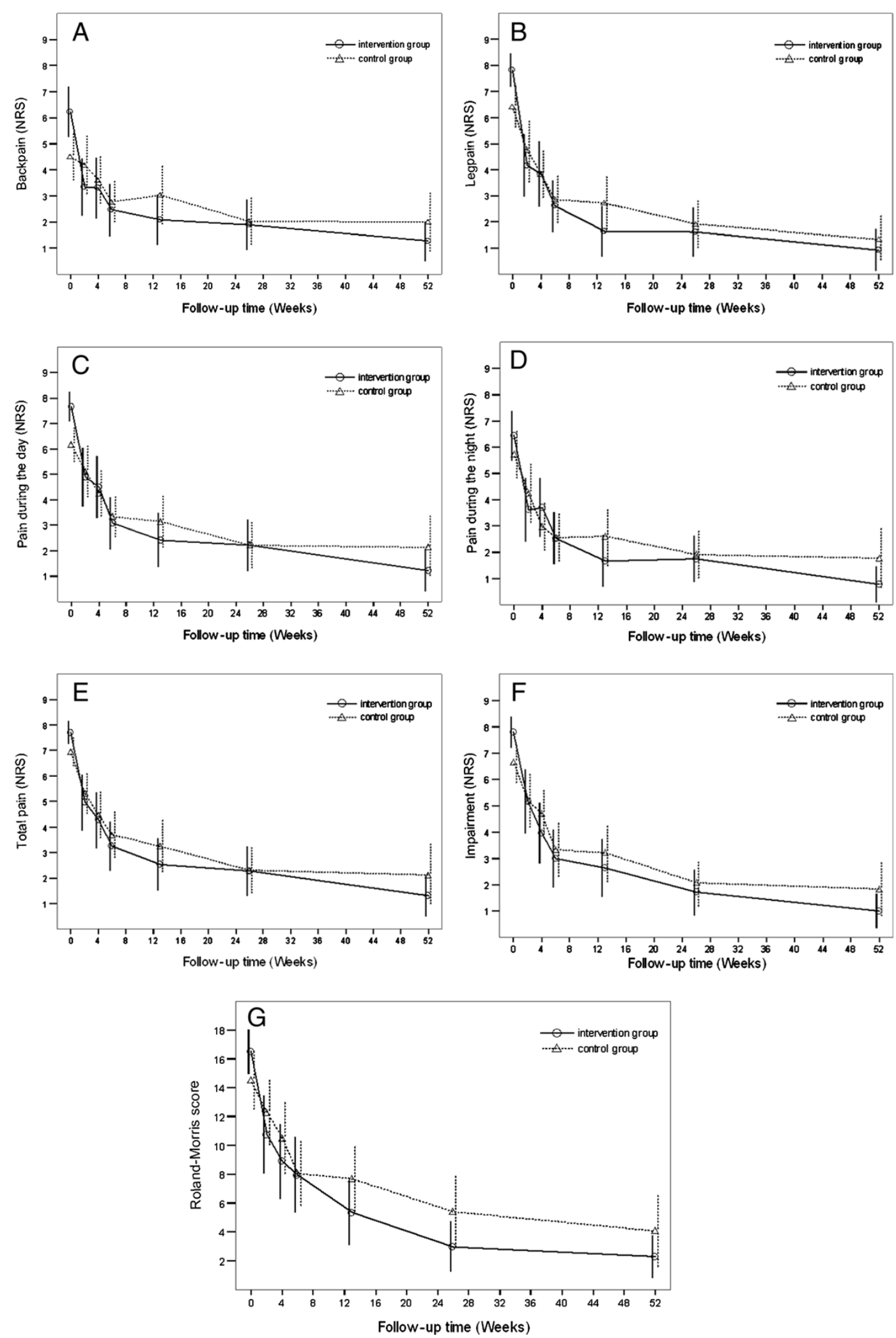

Figure 2 (See legend on next page.) 
(See figure on previous page.)

Figure 2 A-G: results of the mixed model analysis for pain, impairment and Roland-Morris disability scores. When corrected for baseline values, there is a significant effect of the intervention on the RMDQ score and on the NRS scores for back pain and self-perceived impairment (the curve for the intervention group 'lies below' the curve for the control group). The effects are statistically significant but too small to be considered clinically relevant. Differences between groups remain constant over the entire study period (the two curves are parallel).

\section{Results}

Eighty-four patients were presented to us by their GPs, of whom 73 patients were eligible and included in the study. A flow schedule is presented in Figure 1. Ten randomized patients were not included in the analysis. Of these, seven subjects ended their participation shortly after enrollment and three subjects did not send back any questionnaires despite repeated requests. Of one subject the follow-up was incomplete. She died during the study period due to Burkitt lymphoma, which initially caused radicular pain. The subjects lost to follow-up did not differ significantly in sex, age, randomization group or baseline values from the 63 subjects who were included in the analysis. Of these 63 subjects, 30 were men. The mean age of the study participants at the time of the inclusion was 43,7 years (SD 9,8). The intervention group did not differ significantly from the control group in age or distribution of the sexes.

For the 63 study participants, we sent out 441 questionnaires, of which 408 (92,5\%) were returned. Means and standard deviations of all variables in both groups for every time point of measurement are presented in Table 1. The intervention group differed significantly from the control group in all baseline values except for leg pain. In the mixed models regression analysis, these differences were corrected for by including the baseline values as a covariate. In Table 2 and in Figure 2A-G, the results of the mixed models regression analysis are shown. Both groups experience a significant decline over time for all symptoms. The intervention group experienced significantly less symptoms than the control group for the RMDQ-score $(p=0,0173)$, the NRS back pain score $(\mathrm{p}=0,0115)$ and the NRS score for self-perceived impairment $(p=0,0361)$. These differences between the groups remained constant during the whole follow-up period. In Figure 2A-B, the courses over time of all variables for the entire study period are shown graphically.

Finally, we found a significant difference in mean patient satisfaction between the two groups. The intervention group rated their treatment 9,0 on a 0 to 10 scale, and the control group rated their treatment 7,2 on a 0 to 10 scale $(p=0,006)$. No complications or adverse effects of the intervention were reported.

\section{Discussion}

In this study, SESIs yielded a significant overall effect on RMDQ score, back pain, and self-perceived impairment as an additional treatment for LRS in a pragmatic general practice setting. Small differences between pain severity scores and other outcomes, however, may be statistically significant but clinically trivial. As differences of $1.2-2.0$ on the NRS and a $30 \%$ reduction from baseline (which amounts to 4.5 points in our study) in RMDQ score can be considered clinically important to patients, the effects of our intervention are too small to be relevant [24-32].

The intervention group was significantly more satisfied with their treatment than the control group, rating a mean of 9.0 versus 7.2 on a 0 to 10 scale $(p=0,006)$. As no clinically relevant effect was yielded in our study, the more positive evaluation of the intervention by patients should most probably be attributed to the effect of receiving extra attention and care.

Our study is the first pragmatic trial undertaken in general practice, where most patients with LRS are seen and treated in an early stage. It is one of the few studies aimed to assess effectiveness rather than efficacy of SESIs. To our knowledge this has been done only once before, 15 years ago and in a hospital setting [22]. Outcomes of this study suggested that adding SESIs as a first-line treatment to rest and a nonsteroidal antiinflammatory drug for LRS resulted in additional costs and no gain in efficacy. Our study is the first to evaluate the effect of SESIs on LRS with mixed models multiple regression analysis, which enabled us to assess the effect of this intervention over the whole course of the follow-up time rather than evaluating its effect on a single moment. Whereas most trials in this field are underpowered, we included enough patients to yield a statistically significant effect, although it is still a small patient population.

This study has some possible limitations. One is the fact that the intervention group unfortunately differed significantly from the control group in baseline values. Since randomization was adequately performed, we have no explanation for these differences. In the mixed model regression analysis the baseline differences were corrected for by including the baseline values as a covariate. Baseline differences between groups do, however, raise questions about whether those groups are truly comparable. The MCIDs of measuring instruments may vary between categories of baseline severity in symptoms. According to the literature, comparing our groups was allowed [28,33]. We are therefore convinced that the difference in baseline values between our study groups are not a problem for the analyses and the ultimate interpretation of our trial results. 
It can be argued that for our study goals, the RMDQscore would have been a more appropriate primary outcome measure than the NRS back pain score. We chose back pain for calculating our sample sizes because the MCID of the NRS back pain score is extensively used and well described in primary care back pain patients $[24,29,30,32,33]$. The RMDQ, however, is more responsive in sciatica and might in retrospect have been a better choice as primary outcome measure $[24,25,28]$. Considering the outcomes of the RMDQ scores, we can state that our trial would not have been underpowered had we chosen the RMDQ for calculating the sample sizes.

No adverse effects of our intervention were reported by our subjects. One of the subjects, however, died during our study period due to Burkitt lymphoma, which initially caused radicular pain. Epidural steroids are known to relief symptoms of spinal cord compression caused by tumors or metastases [35]. It is conceivable that administering epidural steroids to a patient whose radicular complaints are caused by cancer, delays diagnosis and treatment. To our knowledge, no reports about this problem have been published.

\section{Conclusions}

Placebo-controlled double blinded randomized trials have yielded positive results for the efficacy as a pain treatment of SESIs on LRS. Our study shows that the intervention has a significant beneficial effect as an additional treatment in general practice as well. This effect however, is too small to be considered clinically relevant to patients. Although our patient sample was small, we do not recommend that administering SESIs for the pain treatment of LRS be implemented as a regular intervention in general practice. Further research should be aimed at adequately treating pain in patients with acute LRS with other interventions.

\section{Abbreviations \\ SESI: Segmental epidural steroid injection; CAU: Care as usual; \\ LRS: Lumbosacral radicular syndrome; GP: General practitioner; NRS: Numerical rating scale; BMI: Body mass index; MCID: Minimal clinically important difference; SAS: Statistical analysis software; SD: Standard deviation.}

\section{Competing interests}

The authors declare that they have no competing interests.

\section{Authors' contributions}

AS collected the data, participated in the analysis and wrote the manuscript. JW and MvW participated in the design of the study and including the subjects. They were closely involved in revising all versions of the manuscript. KG performed all analyses, designed the figures and was involved in writing the statistical part of the methods section. All authors read and approved the final manuscript.

\section{Acknowledgements}

The authors would like to thank Prof. Dr. Marjolein Y. Berger, head of the Department of General Practice, Prof. Dr. Klaas van der Meer, emeritus head of the Department of General Practice and Prof. Dr. Mark J.M.K.H. Wierda, emeritus Professor of the Department of Anesthesiology, University Medical Center Groningen, for their help in conducting this study and overseeing the project.
Received: 3 February 2014 Accepted: 13 August 2014

Published: 11 October 2014

\section{References}

1. Mens JMA, Chavannes AW, Koes BW, Lubbers WJ, Ostelo RWJG: [NHGguideline Lumbosacral Syndrome] NHG-standaard Lumbosacraal Radiculair Syndroom. Huisarts en Wetenschap 2005, 48:171-178.

2. Luijsterburg PA, Verhagen AP, Ostelo RW, van Os TA, Peul WC, Koes BW: Effectiveness of conservative treatments for the lumbosacral radicular syndrome: a systematic review. Eur Spine J 2007, 16:881-899.

3. Vroomen PC, de Krom MC, Slofstra PD, Knottnerus JA: Conservative treatment of sciatica: a systematic review. J Spinal Disord 2000, 13:463-469.

4. Saal JS: The role of inflammation in lumbar pain. Spine (Phila Pa 1976) 1995, 20:1821-1827.

5. DePalma MJ, Bhargava A, Slipman CW: A critical appraisal of the evidence for selective nerve root injection in the treatment of lumbosacral radiculopathy. Arch Phys Med Rehabil 2005, 86:1477-1483.

6. McCarron RF, Wimpee MW, Hudkins PG, Laros GS: The inflammatory effect of nucleus pulposus. A possible element in the pathogenesis of low-back pain. Spine 1987, 12:760-764.

7. Nygaard OP, Mellgren SI, Osterud B: The inflammatory properties of contained and noncontained lumbar disc herniation. Spine 1997, 22:2484-2488

8. Arden NK, Price C, Reading I, Stubbing J, Hazelgrove J, Dunne C, Michel M, Rogers P, Cooper C, WEST Study Group: A multicentre randomized controlled trial of epidural corticosteroid injections for sciatica: the WEST study. Rheumatology 2005, 44:1399-1406.

9. Koes BW, Scholten RJ, Mens JM, Bouter LM: Efficacy of epidural steroid injections for low-back pain and sciatica: a systematic review of randomized clinical trials. Pain 1995, 12:279-288.

10. Nelemans PJ, de Bie RA, de Vet HC, Sturmans F: Injection therapy for subacute and chronic benign low back pain. Cochrane Database Syst Rev 2000, 2:1469-1493.

11. Price C, Arden N, Coglan L, Rogers P: Cost-effectiveness and safety of epidural steroids in the management of sciatica. Health Technol Assess 2005, 9:1-58.

12. Hopayian K, Mugford M: Conflicting conclusions from two systematic reviews of epidural steroid injections for sciatica: which evidence should general practitioners heed? Br J Gen Pract 1999, 49:57-61.

13. Karppinen J, Malmivaara A, Kurunlahti M, Kyllonen E, Pienimaki T, Nieminen P, Ohinmaa A, Tervonen O, Vanharanta H: Periradicular infiltration for sciatica: a randomized controlled trial. Spine 2001, 26:1059-1067.

14. Kolsi I, Delecrin J, Berthelot JM, Thomas L, Prost A, Maugars Y: Efficacy of nerve root versus interspinous injections of glucocorticoids in the treatment of disk-related sciatica. A pilot, prospective, randomized, double-blind study. Joint Bone Spine 2000, 67:113-118.

15. Riew KD, Yin Y, Gilula L, Bridwell KH, Lenke LG, Lauryssen C, Goette K: The effect of nerve-root injections on the need for operative treatment of lumbar radicular pain. A prospective, randomized, controlled, double-blind study. J Bone Joint Surg Am 2000, 82:1589-1593.

16. Vad VB, Bhat AL, Lutz GE, Cammisa F: Transforaminal epidural steroid injections in lumbosacral radiculopathy: a prospective randomized study. Spine 2002, 27:11-16.

17. Buchner M, Zeifang F, Brocai DR, Schiltenwolf M: Epidural corticosteroid injection in the conservative management of sciatica. Clin Orthop 2000, 375:149-156.

18. Carette S, Leclaire R, Marcoux S, Morin F, Blaise GA, St Pierre A, Truchon R, Parent F, Levesque J, Bergeron V, Montminy P, Blanchette C: Epidural corticosteroid injections for sciatica due to herniated nucleus pulposus. N Engl J Med 1997, 336:1634-1640.

19. Samanta A, Beardsley J: Sciatica: which intervention? BMJ 1999, 319:302-303.

20. Valat JP, Genevay S, Marty M, Rozenberg S, Koes B: Sciatica. Best Pract Res Clin Rheumatol 2010, 24:241-252.

21. Buenaventura RM, Datta S, Abdi S, Smith HS: Systematic review of therapeutic lumbar transforaminal epidural steroid injections. Pain Physician 2009, 12:233-251.

22. Lafuma A, Bouvenot G, Cohen C, Eschwege E, Fagnani F, Vignon E: A pragmatic cost-effectiveness study of routine epidural corticosteroid injections for lumbosciatic syndrome requiring inhospital management. Rev Rhum Engl Ed 1997, 64:549-555. 
23. Luijsterburg PA, Verhagen AP, Braak S, Oemraw A, Avezaat CJ, Koes BW: General practitioners' management of lumbosacral radicular syndrome compared with a clinical guideline. Eur J Gen Pract 2005, 11:113-118.

24. Lauridsen HH, Hartvigsen J, Korsholm L, Grunnet-Nilsson N, Manniche C: Choice of external criteria in back pain research: Does it matter? Recommendations based on analysis of responsiveness. Pain 2007, 131:112-120.

25. Roland M, Fairbank J: The Roland-Morris Disability Questionnaire and the Oswestry Disability Questionnaire. Spine 2000, 25:3115-3124.

26. Peul WC, Van Houwelingen HC, Van den Hout WB, Brand R, Eekhof JA, Tans $J T$, Thomeer RT, Koes BW: Early surgery or a wait-and-see policy in lumbosacral radicular syndrome: a randomized study. Ned Tijdschr Geneeskd 2007, 151:2512-2523.

27. Peul WC, van Houwelingen HC, van den Hout WB, Brand R, Eekhof JA, Tans JT, Thomeer RT, Koes BW: Surgery versus prolonged conservative treatment for sciatica. N Engl J Med 2007, 356:2245-2256.

28. Jordan K, Dunn KM, Lewis M, Croft P: A minimal clinically important difference was derived for the Roland-Morris Disability Questionnaire for low back pain. J Clin Epidemiol 2006, 59:45-52.

29. Farrar JT, Pritchett YL, Robinson M, Prakash A, Chappell A: The clinical importance of changes in the 0 to 10 numeric rating scale for worst, least, and average pain intensity: analyses of data from clinical trials of duloxetine in pain disorders. J Pain 2010, 11:109-118.

30. Farrar JT, Young JP Jr, LaMoreaux L, Werth JL, Poole RM: Clinical importance of changes in chronic pain intensity measured on an 11-point numerical pain rating scale. Pain 2001, 94:149-158.

31. Kelly AM: The minimum clinically significant difference in visual analogue scale pain score does not differ with severity of pain. Emerg Med J 2001, 18:205-207.

32. Mohan H, Ryan J, Whelan B, Wakai A: The end of the line? The Visual Analogue Scale and Verbal Numerical Rating Scale as pain assessment tools in the emergency department. Emerg Med J 2010, 27:372-375.

33. Collins SL, Moore RA, McQuay HJ: The visual analogue pain intensity scale: what is moderate pain in millimetres? Pain 1997, 72:95-97.

34. Peters SA, Bots ML, Ruijter HM, Palmer MK, Grobbee DE, Crouse JR III, O'Leary DH, Evans GW, Raichlen JS, Moons KG, Koffijberg H: Multiple imputation of missing repeated outcome measurements did not add to linear mixed-effects models. J Clin Epidemiol 2012, 65(6):686-695.

35. Posner JB, Howieson J, Cvitkovic E: "Disappearing" spinal cord compression: oncolytic effect of glucocorticoids (and other chemotherapeutic agents) on epidural metastases. Ann Neurol 1977, 2:409-413.

doi:10.1186/1471-2474-15-341

Cite this article as: Spijker-Huiges et al: Steroid injections added to the usual treatment of lumbar radicular syndrome: a pragmatic randomized controlled trial in general practice. BMC Musculoskeletal Disorders 2014 15:341.

\section{Submit your next manuscript to BioMed Central and take full advantage of:}

- Convenient online submission

- Thorough peer review

- No space constraints or color figure charges

- Immediate publication on acceptance

- Inclusion in PubMed, CAS, Scopus and Google Scholar

- Research which is freely available for redistribution 